\title{
Erratum to: Paraneoplastic disseminated intravascular coagulation caused by splenic littoral cell angioma
}

\author{
Marie Caroline Schlitter • Heiko Rühl • Thore Thiesler • \\ Arndt-Hendrik Penner • Christina Berens • \\ Dominik Wolf • Karin Mayer
}

Published online: 7 May 2014

(C) Springer-Verlag Berlin Heidelberg 2014

\section{Erratum to: Ann Hematol}

\section{DOI 10.1007/s00277-014-2060-x}

The original version of this article inadvertently contained a mistake. The family name of the 5 th author was misspelled and it is corrected here as "Christina Berens".

The online version of the original article can be found at http:// dx.doi.org 10.1007/s00277-014-2060-x.

M. C. Schlitter $\cdot$ D. Wolf $\cdot$ K. Mayer $(\square)$

Medical Clinic III for Oncology, Haematology and Rheumatology,

University Hospital Bonn (UKB), Sigmund-Freud-Straße 25,

53127 Bonn, Germany

e-mail: karin.mayer@ukb.uni-bonn.de

H. Rühl · C. Berens

Institute of Experimental Haematology and Transfusion Medicine,

University Hospital Bonn (UKB), Bonn, Germany

T. Thiesler

Institute of Pathology, University Hospital Bonn (UKB), Bonn,

Germany

\section{A.-H. Penner}

Clinic of Radiology, University Hospital Bonn (UKB), Bonn,

Germany 